\title{
CHALLENGING THE UNITED STATES \\ SYMMETRICALLY AND ASYMMETRICALLY: \\ CAN AMERICA BE DEFEATED?
}

Lloyd J. Matthews

Editor

July 1998

U. S. Army War College

Strategic Studies Institute

Carlisle Barracks, Pennsylvania 